\title{
Evaluación de la calidad fisiológica de semillas de Maytenus vitis-idaea cultivadas in vitro
}

\author{
Assessment of the physiological quality of seeds of Maytenus vitis-idaea cultured in vitro \\ Mirian Bueno $^{a *}$, Claudia Alzugaray ${ }^{\mathrm{a}}$, Graciela Giubileo ${ }^{\mathrm{a}}$, Cecilia Severin ${ }^{\mathrm{a}}$, Nélida Carnevale ${ }^{\mathrm{a}}$ \\ *Autor de correspondencia: aUniversidad Nacional de Rosario, Facultad de Ciencias Agrarias, \\ CC 2125 Zavalla, Santa Fe, Argentina, mbueno@unr.edu.ar
}

\begin{abstract}
SUMMARY
Maytenus vitis-idaea is a bush which reaches 2-5 $\mathrm{m}$ in height. It is found in the Paraguayan-Bolivian Chaco and in the north and central regions of Argentina. In addition to its ecological importance, its leaves were used as salt by the native inhabitants of Paraguay and have medicinal value. The objective of this work was to study the physiological quality of $M$. vitis-idaea seeds cultured in vitro with the purpose to start improvement of biotechnological protocols because its germination is rather unknown and there is no information about in vitro culture for this species. Seeds were tested with the topographical tetrazolium test, and seeds were grown in agar-water (AA) and a medium containing mineral salts and vitamins of Murashige and Skoog (1962) (MS). The following data were recorded: germination percentage, speed of germination (VG) and average time to reach maximum germination (TM). Root and hypocotyls length was measured during 44 days. The tetrazolium test showed $100 \%$ viability of the seeds. Germination percentage was significantly higher in the AA medium (62\%) than in MS medium (36\%) at 20 days after the implantation; germination percentages at 40 days were 92 and 100\% for AA and MS, respectively. In vitro culture of M. vitis-idaea seeds in the medium without mineral salts hastened germination and promoted the vigour of the seeds.
\end{abstract}

Key words: Maytenus vitis-idaea, germination, tissue culture.

\section{RESUMEN}

Maytenus vitis-idaea es un arbusto de $2-5 \mathrm{~m}$ de altura. Se lo encuentra en el Chaco paraguayo-boliviano y norte y centro de Argentina. Además de su importancia ecológica, sus hojas fueron usadas por los indios paraguayos como sal y tienen aplicación medicinal. Con la finalidad de iniciar planes de mejoramiento biotecnológico de M. vitis-idaea, se planteó como objetivo de este trabajo estudiar la calidad fisiológica de las semillas cultivadas in vitro, ya que se trata de una especie poco conocida respecto a su germinación y tampoco se tiene información sobre su cultivo in vitro. Se realizó la prueba topográfica por tetrazolio y se cultivaron semillas in vitro en: agar-agua (AA) y en medio de cultivo con sales minerales y vitaminas de Murashige y Skoog (MS). Se registró: porcentaje de germinación, velocidad de germinación (VG) y tiempo medio para alcanzar la germinación máxima (TM) de las semillas. Se midió la longitud de las raíces y de los hipocótilos durante 44 días. La prueba de tetrazolio arrojó $100 \%$ de viabilidad. El porcentaje de germinación en AA a los 20 días (62\%) fue significativamente superior que en MS (36\%); a los 40 días, los valores de germinación fueron 92 y $100 \%$ para AA y MS, respectivamente. El cultivo in vitro de las semillas de M. vitis-idaea en medio sin sales minerales permite adelantar el proceso de germinación y favorece el vigor de las mismas.

Palabras clave: Maytenus vitis-idaea, germinación, cultivo de tejidos.

\section{INTRODUCCIÓN}

La familia Celastraceae está integrada por unas 430 especies ampliamente distribuidas en todas las zonas tropicales y cálidas templadas del mundo, habiendo sido utilizadas por distintas civilizaciones de Asia, América y África con fines muy diversos y usándose tanto la parte aérea como la raíz (Gupta 1995). De estas plantas se han aislado diversos tipos de metabolitos con actividades biológicas que abarcan un amplio espectro (Gupta 1995). Las especies de esta familia más estudiadas fitoquímicamente pertenecen al género Maytenus y tienen una larga historia de empleo en la medicina popular de varios pueblos (González et al. 1982). Las hojas y tallos preparados en cocimientos son empleados en Argentina en caso de úlceras sangrantes, hipertensión arterial, dolores articulares, como depurativo, contra el asma y antitumoral; la raíz se recomienda como diurético (Toursarkyssyan 1980, Hurrell y Bazzano 2003, Alonso 2006).

Maytenus vitis-idaea Grisebach es conocida como "colquiyuyo", "ibirá-yuqué", "sal del indio", "carne gorda", "tala salado", entre otros. Se lo encuentra en el Chaco paraguayo-boliviano, y norte y centro de Argentina (Jujuy, Salta, Tucumán, Santiago del Estero, Catamarca, 
La Rioja, San Juan, Formosa, Chaco, Corrientes, Santa $\mathrm{Fe}$ y Córdoba) (Cabrera 1965). Florece en septiembreoctubre y fructifica de octubre a diciembre. Es un arbusto de 2-5 $\mathrm{m}$ de altura, cuyo fruto es una cápsula elipsoidea, trígona, de $15 \mathrm{~mm}$ de largo y $7 \mathrm{~mm}$ de diámetro, dehiscente por la abertura de tres valvas. Tiene generalmente tres semillas, subelipsoideas, de $9 \mathrm{~mm}$ de largo y $4 \mathrm{~mm}$ de diámetro, recubiertas por un arilo morado carnoso (Digilio y Legname 1966). Sus hojas fueron usadas por los indios paraguayos como sal y pueden ser empleadas como forrajes (Karlin et al. 1994); tienen también aplicación medicinal como astringente, oftálmica, anticonceptiva y antiasmática. Desde el punto de vista ecológico, la rápida renovación de su materia orgánica hace a esta especie importante para mantener el equilibrio del sistema y contribuir a la restauración de áreas degradadas en los bosques originales.

La germinación de semillas in vitro permite obtener material vegetal para el establecimiento de protocolos de propagación masiva. De esta manera, las plántulas obtenidas pueden ser empleadas como fuentes de explantos asépticos en el cultivo de tejidos. Gutiérrez-Nicolás et al. (2008) informaron la optimización de la germinación de semillas y la multiplicación in vitro de Maytenus canariensis (Loes.) G. Kunkel et Sunding como un medio de propagación para comenzar la explotación biotecnológica de esta especie.

Con la finalidad de iniciar planes de mejoramiento biotecnológico de $M$. vitis-idaea, se planteó como objetivo de este trabajo estudiar la calidad fisiológica de las semillas cultivadas in vitro, ya que se trata de una especie poco conocida respecto a su germinación y tampoco se tiene información sobre su cultivo in vitro.

\section{MÉTODOS}

Se recolectaron frutos de M. vitis-idaea en la Estación Experimental del Ministerio Dr. Tito Livio Coppa en Las Gamas, localidad de Vera, provincia de Santa Fe, Argentina ( $\left.29^{\circ} 30^{\prime} \mathrm{S}, 60^{\circ} 45^{\prime} \mathrm{O}\right)$. Se extrajeron las semillas y se removió el arilo mediante el lavado con agua, posteriormente se secaron en laboratorio a temperatura ambiente y se almacenaron en frascos herméticos de vidrio, a $3^{\circ} \mathrm{C}$, y se utilizaron inmediatamente.

Estas semillas se extrajeron de distintos individuos de la misma población dentro de un quebrachal que es un bosque natural.

Prueba topográfica por tetrazolio. Se humedecieron las semillas 24 horas entre papeles de filtro, se cortó longitudinalmente el tegumento externo y se las colocó 24 horas en solución de cloruro de 2, 3, 5 trifenil tetrazolio al $0,075 \%$ a $30^{\circ} \mathrm{C}$ (Craviotto et al. 1995 , Mudrovitsch de Bittencourt y Vieira 1999). Se hicieron cuatro repe- ticiones de 25 semillas cada una. Para su evaluación, se extrajeron los tegumentos de las semillas y se expresaron los resultados en porcentaje de semillas viables.

Prueba de germinación in vitro. Se desinfectaron las semillas mediante un pasaje por etanol al 96\%, 20 minutos en hipoclorito de sodio al $2 \%$ con dos gotas de Tween 20 y se realizaron tres lavados con agua destilada esterilizada. Los tratamientos fueron: a) sales minerales y vitaminas de Murashige y Skoog (1962) (MS) y b) agua destilada (AA), en ambos casos se adicionaron $7 \mathrm{~g} \mathrm{~L}^{-1}$ de agar y $30 \mathrm{~g} \mathrm{~L}^{-1}$ de sacarosa, el $\mathrm{pH}$ se ajustó a 5,6. La unidad experimental consistió en un tubo con una semilla, se realizaron 20 repeticiones por tratamiento. El diseño experimental fue completamente aleatorizado. La siembra se realizó en tubos de vidrio bajo cámara de flujo laminar y se incubó a $23 \pm 2^{\circ} \mathrm{C}$, con fotoperíodo de $16 \mathrm{~h}$ y una intensidad lumínica de $60 \mu \mathrm{mol} \mathrm{m} \mathrm{m}^{-2} \mathrm{~s}^{-1}$.

Pruebas de vigor in vitro. Se evaluó el vigor de las semillas a través de la velocidad de germinación (VG) propuesto por Kotowiski (1926) [1] y el tiempo medio para alcanzar la germinación máxima (TM) propuesto por Edmond y Drapala (1958) [2]. Se realizaron recuentos diarios de semillas germinadas con radículas a partir de $0,2 \mathrm{~cm}$ de longitud durante 40 días hasta que se estabilizó la germinación. El cálculo de los índices VG y TM se realizó mediante la aplicación de las siguientes fórmulas:

$$
\begin{aligned}
& \mathrm{VG}=\frac{\sum \mathrm{C}_{\mathrm{i}} \times 100}{\sum \mathrm{C}_{\mathrm{i}} \mathrm{T}_{\mathrm{i}}} \\
& \mathrm{TM}=\frac{\sum \mathrm{C}_{\mathrm{i}} \mathrm{T}_{1}}{\sum \mathrm{C}_{\mathrm{i}}}
\end{aligned}
$$

$\mathrm{C}_{\mathrm{i}}$ : número de semillas germinadas por día y $\mathrm{T}_{\mathrm{i}}$ : tiempo.

Se determinó el porcentaje de germinación de las semillas a los 20 y 40 días desde la siembra. Se midió la longitud de las raíces y de los hipocótilos (morfológicamente diferentes) de las plántulas incubadas en ambos medios de cultivo (MS y AA), durante 44 días.

Análisis estadísticos. Los resultados de VG y TM se evaluaron a través de la prueba $\mathrm{T}$ para muestras independientes, previamente se probó la normalidad de los datos en todas las muestras utilizando la prueba de Shapiro Wilks (InfoStat 2004). El porcentaje de germinación se evaluó mediante una prueba de homogeneidad con aplicación de $\chi^{2}$ (chi cuadrado) (SAS/STAT 1990). Para la comparación de la longitud de las raíces y de los hipocótilos de las plántulas en ambas condiciones (AA y MS) y en las distintas fechas de observación, se realizó un análisis longitudinal mediante la utilización 
de modelos mixtos que incorporan la estructura de correlaciones entre observaciones de una misma unidad al modelo, para ambos modelos (longitud de la raíz y del hipocótilo) (SAS/STAT 1990).

\section{RESULTADOS}

A través de la prueba de tetrazolio se determinó un $100 \%$ de viabilidad de las semillas. Las semillas viables fueron aquellas teñidas uniformemente de color rosa en toda su extensión o en los dos tercios de la extensión de los cotiledones, y que pueden presentar pequeñas áreas dañadas observadas en tonos rojo intenso. En las pruebas de germinación in vitro, hubo un $30 \%$ de contaminación a la siembra para las semillas colocadas en ambos tratamientos (AA y MS).

Al analizar el porcentaje de germinación desde la implantación de las semillas en AA, se observó que se concentró la mayor parte de la misma en los primeros 20 días $(62 \%)$, resultado significativamente superior $(P<0,05)$ al obtenido en MS (36\%) (figura 1). A los 40 días desde la siembra in vitro, los valores de germinación obtenidos en ambos tratamientos fueron altos (92 y $100 \%$ para AA y MS, respectivamente) y no se observaron diferencias significativas entre los mismos (figura 1).

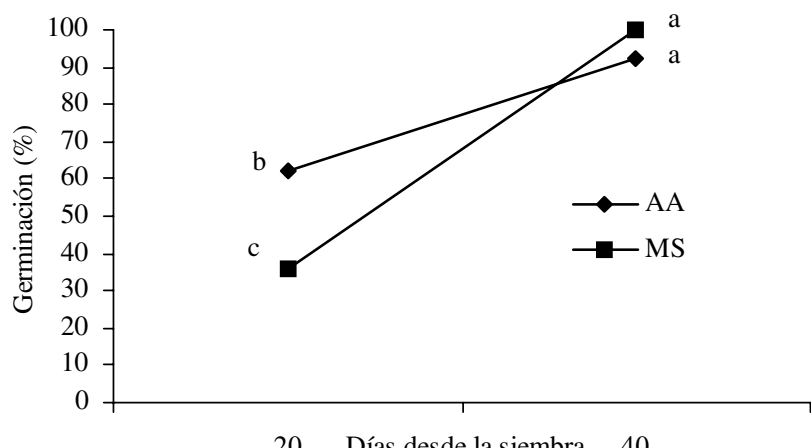

Figura 1. Germinación (\%) a los 20 y 40 días desde la inoculación in vitro de semillas de $M$. vitis-idaea en los medios de cultivo AA y MS. Letras minúsculas iguales indican que no hay diferencias significativas $(P<0,05)$.

Germination (\%) at 20 and 40 days from in vitro implantation of M. vitis-idaea seeds in AA and MS medium. Same letters did not show significant differences between treatments $(P<0.05)$.

La VG como medida de vigor fue $4,9 \%$ y $4,3 \%$ para las semillas colocadas en AA y MS respectivamente. El TM para las semillas en AA fue 20,1 y la respuesta en MS fue 23,1. Aunque no hubo diferencias estadísticamente significativas, las semillas más vigorosas correspondieron a las condiciones sin nutrientes. Un comportamiento similar se manifestó en cuanto a la apertura de los cotiledones, ya que en AA se anticipó nueve días con respecto a MS.
En el crecimiento de la raíz y del hipocótilo se encontró una interacción significativa entre los medios de cultivo (AA y MS) y el tiempo $(P=0,0001)$ (figura $2 \mathrm{~A}$ ), alcanzando valores superiores en medio sin nutrientes. Para la longitud del hipocótilo se obtuvo un modelo donde la interacción fue significativa $(P=0,0443)$ y la diferencia entre los medios de cultivo disminuyó al aumentar el tiempo, de manera que a los 44 días no hubo diferencias significativas (figura 2B).
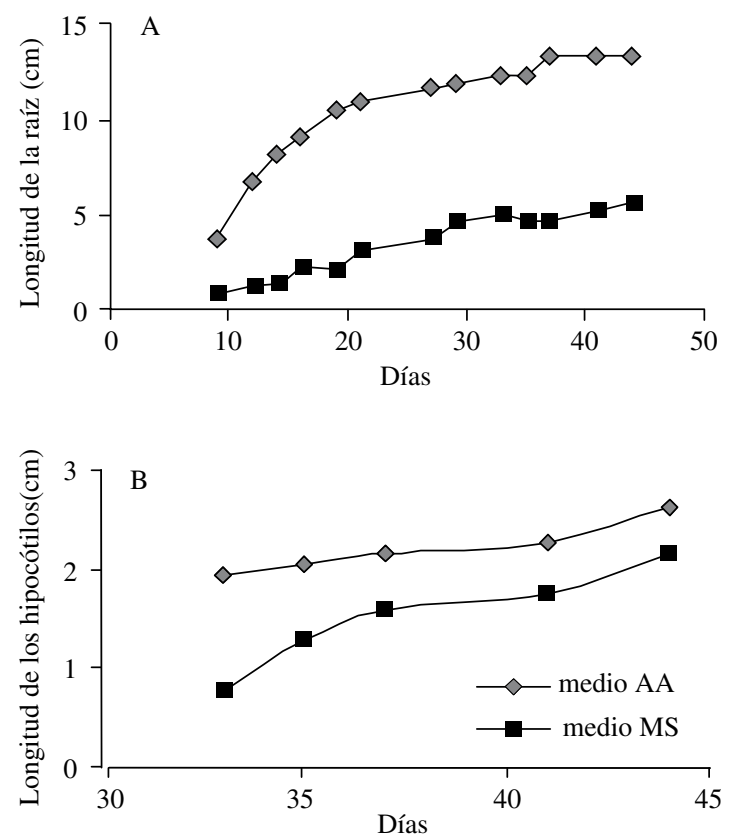

Figura 2. Longitud media de la raíz (A) y de hipocótilos (B) de plántulas de M. vitis-idaea en los medios de cultivo AA y MS.

Average root (A) and hypocotyl (B) length of M. vitis-idaea seedlings grown in AA and MS culture media.

\section{DISCUSIÓN}

En este trabajo los resultados de viabilidad obtenidos por la prueba del tetrazolio se correlacionaron con los altos valores de germinación obtenidos en las dos condiciones de cultivo ensayadas. Sin embargo, Alzugaray ${ }^{1}$ informó que no encontró correlación entre los porcentajes de semillas viables de $M$. vitis-idaea a través de las pruebas del tetrazolio y del poder germinativo.

De acuerdo a lo informado por Cabello y Camelio (1996), en semillas de M. boaria, la remoción del arilo previo a la siembra de las semillas tuvo un efecto significativamente positivo sobre la capacidad germinativa, ya que el arilo inhibe fuertemente la germinación y su eliminación permite superar la latencia. Si bien estos

1 Claudia Alzugaray, Ingeniero Agrónomo, MSc., profesora de Biología de la Facultad de Agronomía (UNR). Comunicación personal. 
investigadores realizaron escarificación mecánica con arena, en nuestro trabajo obtuvimos buenos resultados mediante el lavado de las semillas de $M$. vitis-idaea con agua corriente y su posterior cultivo in vitro.

Eira et al. (1995), que trabajaron con M. ilicifolia Mart. ex Reiss. en condiciones de germinación in vivo, en rollos de papel, obtuvieron a los 35 días porcentajes similares a los hallados a los 40 días en las semillas de M. vitis-idaea con que se hicieron estos ensayos.

En este trabajo se obtuvo hasta un $100 \%$ de germinación, siendo el único tratamiento pregerminativo realizado la eliminación del arilo. Vega et al. (2001) tuvieron un porcentaje de germinación bajo $(24,5 \%)$ en M. vitis-idaea, llegando a valores de $49 \%$ cuando se trataron previamente las semillas con ácido sulfúrico concentrado. Alzugaray ${ }^{1}$, con semillas de la misma especie, sembradas en cajas con arena, llegó a la conclusión que no se justificó aplicar tratamientos pregerminativos a esta especie, tales como lijado y escarificado con ácido sulfúrico en distintas concentraciones.

El porcentaje de germinación in vitro de las semillas de $M$. vitis-idaea en AA a los 20 días fue significativamente superior que en MS. Esta respuesta indicaría que los nutrientes endógenos presentes en los tejidos de las semillas más las dosis agregadas exógenamente retardaron la germinación.

Schuch et al. (1999) citan que semillas con alto vigor tuvieron sus procesos metabólicos acelerados, propiciando una emisión más rápida y uniforme de sus raíces primarias, que resultó en un mayor tamaño inicial de las microplantas. Según estos autores, el tamaño de las raíces fue más adecuado que la longitud de la parte aérea para las evaluaciones de diferencias en el vigor entre lotes de semillas de avena negra. La estimación del vigor de las semillas también puede ser realizada a través del crecimiento de las plantas utilizando la longitud total o de sus órganos, de manera que el crecimiento de las plantas es considerado una prueba de vigor (AOSA 1983). En este trabajo, las plantas más vigorosas se manifestaron en el medio sin nutrientes minerales y el crecimiento tanto de las raíces como del hipocótilo fue significativamente mayor. Por lo tanto, es de suponer que las plantas obtenidas en este medio tendrán un buen comportamiento a campo. Según Teckrony y Egli (1991), el vigor de las plántulas observado en el campo por la habilidad de las semillas en emerger y crecer rápida y vigorosamente, es un factor que puede influenciar la productividad de los cultivos.

Como conclusión se puede expresar que el cultivo in vitro de las semillas de $M$. vitis-idaea en medio sin sales minerales, permite adelantar el proceso de germinación $\mathrm{y}$ favorece el vigor de las mismas.

\section{REFERENCIAS}

Alonso J. 2006. Plantas medicinales autóctonas de la Argentina. Bases Científicas para su aplicación en atención primaria de la salud. Bs. As., Argentina. Fitociencia. 663 p.

AOSA (Association of official seed analysts, US). 1983. Seed vigour testing handbook. Lincoln. East Lansing. 88 p.

Cabello A, ME Camelio. 1996. Germinación de semillas de Maitén (Maytenus boaria) y producción de plantas en vivero. Ciencias Forestales 11(1-2): 3-17.

Cabrera A. 1965. Colección Científica del INTA. Tomo IV, Parte $4^{a}$. Bs. As. Argentina. p.136-137.

Craviotto RM, M Fared, M Montero. 1995. Prueba topográfica por tetrazolio. Patrones para la especie soja. Laboratorio de semillas. Santa Fe, Argentina. INTA. Centro Reg. E.E.A. Oliveros. 20 p.

Digilio A, P Legname. 1966. Los árboles indígenas de la provincia de Tucumán. Universidad Nacional de Tucumán, Instituto Miguel Lillo. Opera Lilloana 15: 67. Tucumán, Argentina.

Edmond JB, WJ Drapala. 1958. The effect of temperature, sand and soil, and acetone on germination of okra seed. Proceeding of the American Society for Horticultural Science 71: 738-34.

Eira M, T Dias, C Mello. 1995. Comportamiento fisiológico de sementes de espinheira santa Maytenus ilicifolia no armazenamento. Horticultura Brasileira 13 (1): 32-34.

González J, G Delle-Monache, F Delle-Monache, GB MariniBettolo. 1982. Chuchuhuassha-drug used in Fol. Medicine in the Amazonian and Andean areas. Chemical study of Maytenus laevi. J. Ethnopharmacol 5: 73-77.

Gutiérrez-Nicolás F, AG Ravelo, R Zárate. 2008. Seed germination and in vitro propagation of Maytenus canariensis through regeneration of adventitious shoots from axillary and apical buds. Biologia Plantarum 52 (1): 173-176

Gupta M. 1995. 270 Plantas Medicinales Iberoamericanas. Programa Iberoamericano de Ciencia y Tecnología para el Desarrollo. Santa Fe de Bogotá. Colombia. CYTED. 617 p.

Hurrell JA, DH Bazzano. 2003. Arbustos I Nativos y Exóticos. Biota Rioplatense VIII. Bs. As., Argentina. L.O.L.A. 263 p.

InfoStat 2004. Versión 2004. Manual del Usuario. Grupo InfoStat, FCA, Universidad Nacional de Córdoba. Córdoba, Argentina. Brujas Argentinas. 314 p.

Karlin U, L Catalán, R Coirini. 1994. La naturaleza y el hombre en el Chaco Seco. Facultad de Ciencias Agropecuarias. UNC. Proyecto GTZ. Desarrollo Agroforestal en Comunidades del Noroeste Argentino. Salta, Argentina. 163 p.

Kotowiski F. 1926. Temperature relations to germination of vegetable seeds. Proc. Amer. Soc. Hort. Sci. 23: 176-184.

Mudrovitsch de Bittencourt PR, DR Vieira. 1999. Metodología do Teste de Tetrazólio em Sementes de Amendoim. In Krzyzanowski FC, R Dalton Vieira, J Frama Neto ed. Vigor de Sementes: Conceitos y Testes. ABRATES. Londina Pr, Brasil. p. 1-28.

Murashige T and F Skoog. 1962. A revised medium for rapid growth and bioassays with tobacco tissue cultures. Physiologia Plantarum 15: 473-497.

SAS/STAT (Statistical Analysis System Institute, US). 1990. Versión 6. SAS Inst. Inc. Cary, NC. EEUU. 
Schuch LOB, JL Nedel, JN De Assis, M De Souzza Maia. 1999. Crescimento em laboratório de plántulas de aveia preta (Avena strigosa Schreb.) em funçao do vigor de sementes. Revista Brasileira de Sementes 21 (1): 229-234.

Teckrony MD, DB Egli. 1991. Relationship of seed vigour to crop yield: a review. Crop Science 31: 816-822.
Toursarkyssyan M. 1980. Plantas medicinales de la Argentina. Bs. As., Argentina. Hemisferio Sur. 178 p.

Vega L, G Turco, C Alzugaray, N Carnevale, A Salinas. 2001. Viabilidad y vigor en semillas de Maytenus vitis-idaea (Gris). XXI Reunión Anual de la Sociedad de Biología de Rosario. p. 38.

Recibido: 21.01 .09

Aceptado: 06.07.09 